\title{
ESTUDO DA CINÉTICA DE FLOTAÇÃO CATIÔNICA DE REJEITOS DE MINÉRIO DE FERRO
}

\section{STUDY OF THE KINETICS OF CATIONIC FLOTATION OF IRON ORE WASTE}

\author{
T. E. LOPES ${ }^{1}$, S. O. FREITAS ${ }^{2}$, N. F. SOUZA ${ }^{1}$, A. R. A. PINTO ${ }^{1}$ and A. B. REIS ${ }^{1 *}$ \\ ${ }^{1}$ UFVJM - Universidade Federal dos Vales do Jequitinhonha e Mucuri, Engenharia Química, Diamantina-MG/Brasil \\ ${ }^{2}$ UFVJM - Universidade Federal dos Vales do Jequitinhonha e Mucuri, Engenharia Geológica, Diamantina-MG/Brasil
}

${ }^{*}$ Corresponding author.

e-mail address: arlete.reis@ict.ufvjm.edu.br

\begin{tabular}{|c|}
\hline A R T I C L E I N F O \\
\hline $\begin{array}{l}\text { Article history: } \\
\text { Received 2020-06-30 } \\
\text { Accepted 2020-12-12 } \\
\text { Available online 2020-12-12 }\end{array}$ \\
\hline $\begin{array}{l}\text { palavras-chave } \\
\text { Coletor } \\
\text { Depressor } \\
\text { Transferência de massa } \\
\text { Espectroscopia }\end{array}$ \\
\hline $\begin{array}{l}\frac{k e y w o r d s}{\text { Collector }} \\
\text { Depressor } \\
\text { Mass transference } \\
\text { Spectroscopy }\end{array}$ \\
\hline
\end{tabular}

\begin{abstract}
A B S T R A C T
Flotation is a mixture separation technique, characterized by the involvement of the liquid, solid and gaseous phases. This operation is used to separate hydrophobic particles from hydrophilic particles. It consists of adding air bubbles to the medium, which causes the hydrophobic particles suspended in the liquid to adhere to these bubbles, causing the formation of foam that can then be removed, dragging the particles of impurities with them. This work is of particular interest in the experimental study of the reverse flotation process in order to recover minerals of interest, such as iron minerals, present in tailings from the mining industry, aiming above all for reuse in future applications.
\end{abstract}

R E S U M O

A flotação é uma técnica de separação de misturas, caracterizada pelo envolvimento das fases líquida, sólida e gasosa. Essa operação é utilizada para separar partículas hidrofóbicas de partículas hidrofílicas. Consiste em adicionar bolhas de ar ao meio, que faz com que as partículas hidrofóbicas em suspensão no líquido passem a aderir-se a essas bolhas, ocasionando a formação de espuma que podem ser então removidas, arrastando consigo as partículas de impurezas. Este trabalho apresenta particular interesse no estudo experimental acerca do processo de flotação reversa com o intuito de recuperar minerais de interesse, como por exemplo, minerais de ferro, presentes em rejeitos da indústria de mineração, visando sobretudo o reaproveitamento em aplicações futuras. 


\section{INTRODUÇ̃̃̃O}

No Brasil, a exploração do minério de ferro se faz presente desde o ciclo do ouro, com uma necessidade de produção de ferramentas para agricultura e a própria extração, tornando-o referência mundial na produção de aço, dada a abundância de jazidas de ferro e disponibilidade de carvão que, paralelamente, resultou no aumento do consumo de minério de ferro (DUARTE, 2019). Concomitantemente, devido ao rápido crescimento populacional e volume de exportações, a demanda por recursos minerais como o ferro tem disparado nos últimos anos (PENNA et al., 2003).

Como o minério não é um produto renovável, as jazidas de alta concentração de minério aproximam cada vez mais de sua capacidade máxima de extração, fazendo com que mineradoras busquem outras formas de tratamento mineral mais complexos e com exploração de baixos teores (PENNA et al., 2003) como o estudo de processo de separação e beneficiamento.

Com o avanço das tecnologias, as indústrias minerais estão sujeitas a produzir materiais mais específicos e com menores custos. Neste sentido, a flotação é um processo de concentração mineral desenvolvido para tentar recuperar os minérios de menores teores que são perdidos na extração do mineral de maior teor (PENNA et al., 2003).

No processo de flotação mineral, o ar é borbulhado através de uma polpa de minério, e reagentes com funções específicas são adicionados à polpa. No caso da flotação de minério de ferro, esses reagentes tem o objetivo de modificar a superfície dos óxidos de ferro ou silicatos para que essas partículas possam seletivamente se aderir nas bolhas de ar para serem conduzidas até a superfície, onde serão removidas em forma de espuma. (LOPES, 2009).

Durante a flotação, ocorre o fenômeno de transferência de massa, onde o ar transporta matéria da polpa para a espuma formada (LABIDI et al., 2006). As indústrias de mineração comumente utilizam-se das barragens de rejeitos, que são estruturas construídas visando a disposição dos materiais não aproveitados, tendo normas intrínsecas para sua implantação, impedindo que esses rejeitos infiltrem no solo e nos lençóis freáticos contaminando o meio com metais pesados $\mathrm{e}$ substâncias nocivas (IBRAM, 2016).

Em novembro de 2015 uma barragem de rejeitos no município de Mariana, no estado de Minas Gerais Fundão, veio a romper. Esse acidente acabou lançado uma grande quantidade de lama que causou grandes danos nas vizinhanças e posteriormente expandiu para outras regiões através do rio em que a lama se depositou. A barragem de Fundão, como era chamada, pertencia a mineradora Samarco. Informações da própria empresa aprontam que aproximadamente 40 milhões de metros cúbicos de rejeitos de minério de ferro foram liberados. Nesse rejeito estavam presentes sedimentos e substâncias tóxicas em níveis elevados (BRASIL \& PIRES, 2017). Em janeiro de 2019 uma nova barragem de rejeitos de minério de ferro, associada à mineradora Vale S.A., em Brumadinho (MG) também se rompeu (PEREIRA et al., 2019). Esses desastres trouxeram prejuízos à sociedade, para o meio físico, biótico e socioeconômico que são imensuráveis (ANGOTTI et al., 2019).
No âmbito desse contexto, o presente trabalho teve como objetivo principal, iniciar estudos no intuito de promover a recuperação dos minerais presentes em amostras de rejeitos da indústria de mineração e consequentemente reduzir a deposição dos rejeitos em barragens. Para tanto foi realizado estudo acerca da transferência de massa durante o processo de flotação, a partir de um planejamento fatorial do tipo $2^{2}$ tendo como variáveis a concentração da polpa e a vazão de ar na flotação catiônica reversa como um processo de recuperação, analisando a cinética de transferência de massa, refletida na possibilidade de separação das frações.

\section{MATERIAL E MÉTODOS}

\subsection{Material}

Durante o desenvolvimento do trabalho foram utilizados os seguintes materiais: Amostras de rejeito de mineração; Amido de milho (comercial) gelatinizado com $\mathrm{NaOH}$, amina $\mathrm{EDA}, \mathrm{HCl}, \mathrm{NaOH}$, água destilada; Balança analítica, estufa, módulo de flotação horizontal;

O material no qual foi aplicado a técnica de flotação foram amostras de rejeito de mineração cedidos pela empresa Samarco coletada na Usina de Risoleta Neves, conhecida como candonga, localizada no município de Santa Cruz do EscalvadoMG.

Os experimentos foram realizados em uma célula mecânica, sendo ela um módulo didático "flotador horizontal" da empresa UpControl para a realização da prática, como mostrado na Figura 1.

\subsection{Métodos}

Neste trabalho foi realizado o processo de flotação catiônica reversa com objetivo de recuperar a hematita. A polpa foi ajustada para um de $\mathrm{pH}$ para 10,5, utilizou-se o amido de milho comercial, como depressor e amina EDA, como coletor.

O processo da flotação foi realizado a partir do planejamento fatorial do tipo $2^{2}$ com duas repetições do ponto central, tendo como variáveis manipuladas, a concentração da polpa e a vazão de ar. Os valores adotados no planejamento fatorial podem ser observados na Tabela 1. Os valores das concentrações foram definidos de acordo com a literatura (PIUZZANA et al., 2015). Em cada concentração, o pH da polpa foi corrigido para 10,5, com adição de hidróxido de sódio $(\mathrm{NaOH})$ e ácido clorídrico (HCl), (PIUZZANA et al., 2015). A polpa foi transferida para o flotador, logo após, o rotor foi ligado a uma velocidade de $1500 \mathrm{rpm}$. Para aeração do sistema foi utilizado um compressor com uma vazão de ar comprimido (Tabela 1). Com a polpa em agitação adicionou-se o amido gelatinizado e após 5 minutos, adicionou-se à polpa a amina EDA, e os reagentes introduzidos foram quantificados de acordo com a concentração de cada experimento. 


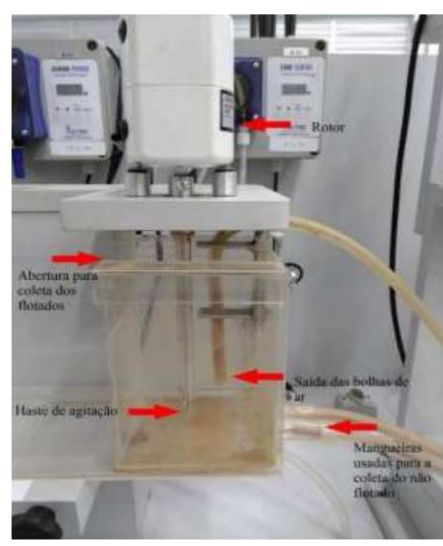

\section{Figura 1 - Equipamento utilizado na flotação reversa.}

O processo da flotação foi realizado a partir do planejamento fatorial do tipo $2^{2}$ com duas repetições do ponto central, tendo como variáveis manipuladas, a concentração da polpa e a vazão de ar. Os valores adotados no planejamento fatorial podem ser observados na Tabela 1. Os valores das concentrações foram definidos de acordo com a literatura (PIUZZANA et al., 2015). Em cada concentração, o pH da polpa foi corrigido para 10,5, com adição de hidróxido de sódio $(\mathrm{NaOH})$ e ácido clorídrico (HCl), (PIUZZANA et al., 2015). A polpa foi transferida para o flotador, logo após, o rotor foi ligado a uma velocidade de $1500 \mathrm{rpm}$. Para aeração do sistema foi utilizado um compressor com uma vazão de ar comprimido (Tabela 1). Com a polpa em agitação adicionou-se o amido gelatinizado e após 5 minutos, adicionou-se à polpa a amina EDA, e os reagentes introduzidos foram quantificados de acordo com a concentração de cada experimento.

Tabela 1 - Dosagens de depressor e coletor usados nos ensaios de flotação.

\begin{tabular}{ccc} 
Concentrações & Depressor $(\mathrm{mL})$ & Coletor $(\mathrm{mL})$ \\
$25,0 \%$ & 2,50 & 1,00 \\
$37,5 \%$ & 4,70 & 1,88 \\
$50,0 \%$ & 10,00 & 4,00 \\
\hline
\end{tabular}

A coleta do concentrado foi feita manualmente a cada minuto durante um intervalo de 8 minuto e, cada amostra de concentrado foi disposta em béqueres. Após o término do experimento, o material coletado foi seco, pesado e, em seguida, foram efetuados os cálculos da massa acumulada.

Tabela 2 - Parâmetros adotados no planejamento $2^{2}$.

\begin{tabular}{ccc} 
Ensaio & $\begin{array}{c}\text { Concentração } \\
\text { de sólidos na } \\
\text { polpa }\end{array}$ & $\begin{array}{c}\text { Vazão de ar } \\
\text { (NL/h) }\end{array}$ \\
\hline 1 & $50,0 \%$ & 200 \\
2 & $50,0 \%$ & 400 \\
3 & $25,0 \%$ & 400 \\
4 & $25,0 \%$ & 200 \\
5 & $37,5 \%$ & 300 \\
6 & $37,5 \%$ & 300 \\
\hline
\end{tabular}

\section{RESULTADOS}

Na Figura 2 são mostrados os resultados da cinética de recuperação mássica para cada ensaio do planejamento fatorial, sendo possível observar que o comportamento das curvas é semelhante ao observado na literatura.

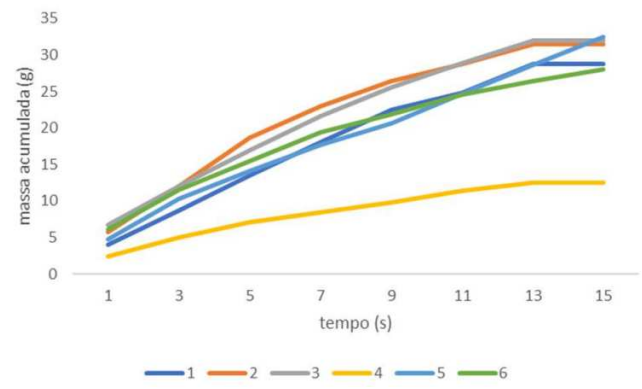

Figura 2 - Curva de velocidade de transferência de massa.

Observa-se que a curva 4 é destacada das demais curvas e acaba apresentando um valor de massa acumulada abaixo das outras curvas. Assim, podemos concluir que uma baixa concentração e baixa vazão não favorecem o acúmulo de massa na flotação.

Outra observação possível é que nos ensaios em que a concentração é a mesma, o maior acúmulo de massa no ensaio que tiver a maior vazão de ar. Em relação à concentração, podemos observar que as curvas 2 e 3 que possuem mesma vazão, porém a concentração do ensaio 2 é maior. Ainda assim as curvas mostram que o acúmulo mássico em ambos os ensaios se mostrou semelhantes.

A curvas 2 e 3 se destacaram em relação às demais quanto a massa acumulada total. Dessa forma, essas curvas tiveram seus pontos iniciais e finais submetidos à análise de FTIR, com objetivo de avaliar as composições em cada ponto.

\subsection{Análise de espectroscopia de infravermelho por} transformada de Fourier

O método de espectroscopia de infravermelho por transformada de Fourier (FTIR) consiste em investigar os grupos funcionais presentes na amostra. Desta forma, a Figura 3 demonstra como a análise por infravermelho do rejeito flotado se comporta.
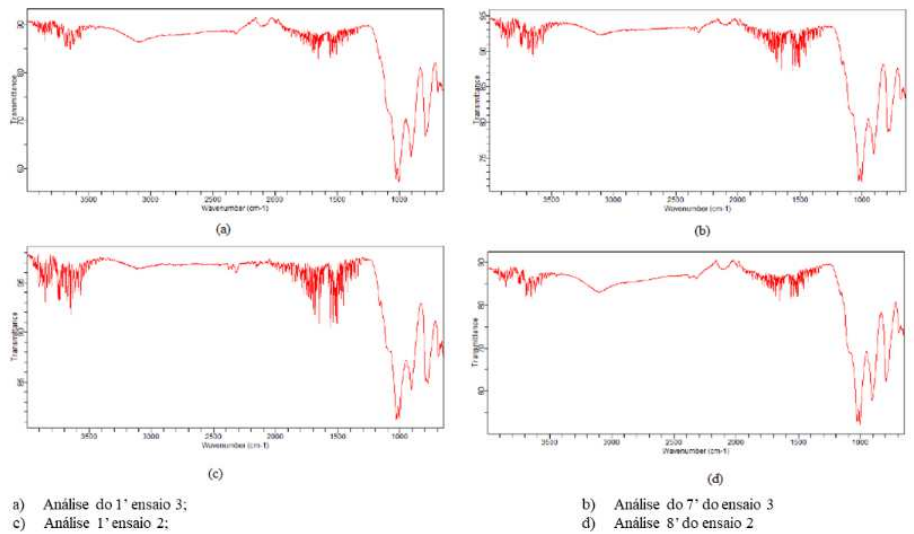

Figura 3 - Análise de espectroscopia de infravermelho por transformada de Fourier.

Segundo Lopes (2009), a composição mineralógica do rejeito do minério de ferro apresenta entre diversos compostos, hematita $\left(\mathrm{Fe}_{2} \mathrm{O}_{3}\right)$ e quartzo $\left(\mathrm{SiO}_{2}\right)$. Esses componentes são os principais alvos da flotação catiônica. Os resultados obtidos na análise FTIR (Figura 3), mostram que nos ensaios 2 e 3 tanto no primeiro ponto quanto no último, existe a presença de hematita e quartzo. 
De acordo com a literatura, nas análises de infravermelho, as bandas que ocorrem entre 1000 a $1100 \mathrm{~cm}_{-1}$ é caracterizada pelo quartzo $\left(\mathrm{SiO}_{2}\right)(\mathrm{AWADH}, 2019)$. Segundo Cardoso (2018), as bandas entre 700 a $900 \mathrm{~cm}^{-1}$ está caracterizado hematita $\left(\mathrm{Fe}_{2} \mathrm{O}_{3}\right)$. Pode-se perceber, que essa qualificação está de acordo com o esperado.

\section{CONCLUSÃO}

A partir da realização do ensaio de flotação por espuma, foi possível observar que este é um método altamente versátil para a separação física de partículas com base nas diferenças na capacidade das bolhas de ar aderirem seletivamente às superfícies minerais específicas na polpa.

Avaliando qualitativamente é possível observar que maiores vazões ocasionaram maior acúmulo de massa no processo de flotação. Em relação a concentração, os resultados são inconclusivos quanto ao acúmulo de massa. Análises de espectroscopia de infravermelho por transformada de Fourier foram realizadas nos ensaios que apresentaram maiores valores de massa acumulada, onde, com base na literatura os picos apresentaram características dentro do esperado. Notou-se que para as amostras que tiveram maior acúmulo de massa, provavelmente está relacionado aos picos do FTIR, pois ocorreu maior estiramento assimétrico das ligações, ou seja, maior presença e quantidade do quartzo $\left(\mathrm{SiO}_{2}\right)$ e da hematita $\left(\mathrm{Fe}_{2} \mathrm{O}_{3}\right)$.

Uma vez realizada essa avaliação qualitativa, pode-se pensar para o futuro avaliações quantitativas afim de avaliar se as faixas trabalhadas afetaram também as recuperações minerais. Podem ser avaliados também outros parâmetros como reagentes, o tipo de gás inserido etc.

\section{AGRADECIMENTOS}

Os autores agradecem à FAPEMIG, projeto APQ03624-17 Rede Candongas: Aplicação de Tecnologias Desenvolvidas e Estudos de Viabilidade Técnica e Econômica para a Transformação e Valoração dos Rejeitos Dragados da Barragem de Candongas (Transformando o Desastre do Rio Doce em Oportunidades Locais). Aos laboratórios LIPEMVALE-UFVJM; Ao LMMA financiado pela FAPEMIG (CEX-112-10), SECTES/MG e RQ-MG. Ao GEPAEQ-Grupo de Estudos e Pesquisas Aplicadas à Engenharia Química.

\section{R E F E R E N C I A S}

ANGOTTI, M.; FERREIRA, A. C. S., EUGENIO, T. C. P. Full cost accounting e contabilidade dialógica aplicados para avaliação da (in)sustentabilidade da mineração: $o$ caso de Congonhas (MG). Universidade Federal do Rio de Janeiro, 2019.

AWADH, S. M.; YASEEN, Z. M. Investigation of silica polymorphs stratified in siliceous geode using FTIR and XRD methods. Materials Chemistry and Physics, v. 228, p. 45-50, 2019.
BRASIL, L. M.; PIRES, V. O que a lama nos deixou: reflexões sobre a tragédia de mariana, a mídia e a mineração no brasil. Observatoire des amériques montréal, v. 17, n. 3, 2017.

CARDOSO, E. Ri. Nanotubos de carbono decorados com óxido de ferro aplicados a sensores de gás. 2018. Dissertação de Mestrado. Universidade Tecnológica Federal do Paraná.

DUARTE, H. A. Ferro - Um elemento químico estratégico que permeia história, economia e sociedade. Quím. Nova, São Paulo, v. 42, n. 10, p. 1146-1153, 2019.

IBRAM - Instituto Brasileiro de Mineração. Gestão e Manejo de Rejeitos da Mineração. Organizador: Instituto Brasileiro de Mineração. 1.ed. Brasília: IBRAM, 2016.

LABIDI, J.; PÈLACH, M.A.; TURON, X.; MUTJÉ, P. Predicting flotation efficiency using neural networks. Chem. Eng. and Processing: Process Intensification, v. 46, n. 4, p. 314-322, 2007.

LOPES, G. M. Flotação direta de minério de ferro. 2009. $176 \mathrm{f}$. Dissertação (Mestrado em Engenharia Mineral) Universidade Federal de Ouro Preto, Ouro Preto, 2009.

PENNA, R; OLIVEIRA, M. L. M.; VALADAO, G. E. S.; PERES, A. E. C. Estudo comparativo entre dois sistemas de aeração de coluna de flotação. Rem: Revista Escola de Minas. 2003, vol.56, n.3, p.195-200.

PEREIRA, L. F.; CRUZ, G. B.; GUIMARÃES, R. M. F. Impactos do rompimento da barragem de rejeitos de Brumadinho, Brasil: uma análise baseada nas mudanças de cobertura da terra. Journal of Environmental Analysis and Progress, v. 4, n. 2, p. 122-129, 2019.

PIUZZANA, G; MACHADO, H; ETRUSCO, I; BIGÃO, L; LÉLIS, M; DINALLI, R. Flotação. Faculdade de Engenharia da Universidade Estadual de Minas Gerais, João Monlevade-MG, 2015. 